\title{
Development of fire shutters based on numerical optimizations
}

\author{
Ondrej Novak ${ }^{1, \mathrm{a}}$, Petr Kulhavy ${ }^{1}$, Tomas Martinec ${ }^{1}$, Michal Petru ${ }^{1}$ and Pavel Srb ${ }^{1}$ \\ ${ }^{1}$ Institute for Nanomaterials, Advanced Technologies and Innovation, Technical University of Liberec, Studentská 2 , \\ 461 17, Liberec 1, Czech Republic
}

\begin{abstract}
This article deals with a prototype concept, real experiment and numerical simulation of a layered industrial fire shutter, based on some new insulating composite materials. The real fire shutter has been developed and optimized in laboratory and subsequently tested in the certified test room. A simulation of whole concept has been carried out as the non-premixed combustion process in the commercial final volume sw Pyrosim. Model of the combustion based on a stoichiometric defined mixture of gas and the tested layered samples showed good conformity with experimental results - i.e. thermal distribution inside and heat release rate that has gone through the sample.
\end{abstract}

\section{Introduction}

Fire safety is an inseparable aspect during the buildings design. One of the basic requirements especially for industrial buildings is dividing the building into fire zones, each other protected by fire partition structures, to prevent spreading of a potential fire and minimization looses. In our case some light fireproof materials that are used in fast fire barriers (e.g. movable gate, blinds) have been tested. Their function is to create a thermal shield between place which should stay safe and cool even if they are affected by high temperature radiation and convection from a near heat sources at the other side [1] for a by declared standard given time.

This article deals with numerical and experimental study of thermal transfer between flame of a propan butan jet and measured layered samples. Solving of a similar problem requires simultaneously application of several disciplines. Fire safety comprises a significant area of materials, design and technology research that bring the safety of buildings and another constructions. Fire shutters are designed to protect not only a property but especially health and lives. Fulfilment of the demanding requirements of fire shutters will provide sufficient time for evacuation after a fire outbreak, but also increase the time required for to reach of the place of fire by fire fighters [2]. The issue of designing and testing of heat-resistant materials and fire shutters is very complex. The reason for that is the complexity of the physical nature of the flame construction process. The reason can be found in the complicated physical nature of the burning process and its impact on the fire construction. The problem lies in the combination of multiple heat transfer mechanisms from heat source to construction and also in fire-resistant construction. While in conventional structures at normal temperatures, the heat transfer is predominantly realised by the conduction,

\footnotetext{
a Corresponding author: ondrej.novak@tul.cz
}

at high temperatures there is also a significant influence of radiation transmission. Another problem is the unsteady behavior of materials, because thermal insulation properties vary with temperature, but very often manufacturers specify only one value. Therefore, in the modelling process, it is necessary to take this fact into account and to set the coefficients of the material model based on the results of real measurements carried out on reduced scale models of fire doors. Only after tuning material model and obtaining the corresponding FE models the virtual prototyping using modelling can begin.

\section{Materials and methods}

Standardized test $[3,4]$ is conducted in a special chamber where the process of fire simulating two LPG burners while the mass flow of fuel and oxidant could be regulated.

A homogenous distribution of the temperature in testing chamber is required for corresponding data of tests that are used for construction optimization of fire doors. Temperature distribution in the testing chamber near of sample was tested during measurement cycle. The temperature curve is prescribed with equation (1).

$$
\mathrm{T}=345 \log [8(t-20)+1]+20
$$

Where $t$ is time in minutes and $T$ is required temperature in the chamber in Celsius degree.

\subsection{Fireproof layered sample}

The fire door is composed of five individual layers. Applied materials are put without air gape. The 
composition of this sandwich is put in Table 1. and the real segment of the tested shutter could be seen in Fig.1.

Table 1. Composition of sandwich

\begin{tabular}{|l|c|c|c|c|}
\hline Material & $\begin{array}{c}\text { Thickness } \\
{[\mathrm{mm}]}\end{array}$ & $\begin{array}{c}\text { Density } \\
{\left[\mathrm{kg} \cdot \mathrm{m}^{-3}\right]}\end{array}$ & $\begin{array}{c}\text { Specific heat } \\
\text { capacity in } \\
\text { the dry state } \\
{\left[\mathrm{J} \cdot \mathrm{kg}^{-1} \cdot \mathrm{K}^{-1}\right]}\end{array}$ & $\begin{array}{c}\text { Thermal } \\
\text { conductivity } \\
\text { coefficient } \\
\lambda\left[\mathrm{W} \cdot \mathrm{m}^{-1} \cdot \mathrm{K}^{-1}\right]\end{array}$ \\
\hline $\begin{array}{l}\text { Steel } \\
\text { (zinc } \\
\text { coating) }\end{array}$ & 1 & 7850 & 490 & 50 \\
\hline Gypsum & 12,5 & 750 & 1060 & 0,22 \\
\hline $\begin{array}{l}\text { Mineral } \\
\text { wool }\end{array}$ & 60 & 200 & 880 & 0,064 \\
\hline Gypsum & 12,5 & 750 & 1060 & 0,22 \\
\hline $\begin{array}{l}\text { Steel } \\
\text { (zinc } \\
\text { coating) }\end{array}$ & 1 & 7850 & 490 & 50 \\
\hline
\end{tabular}

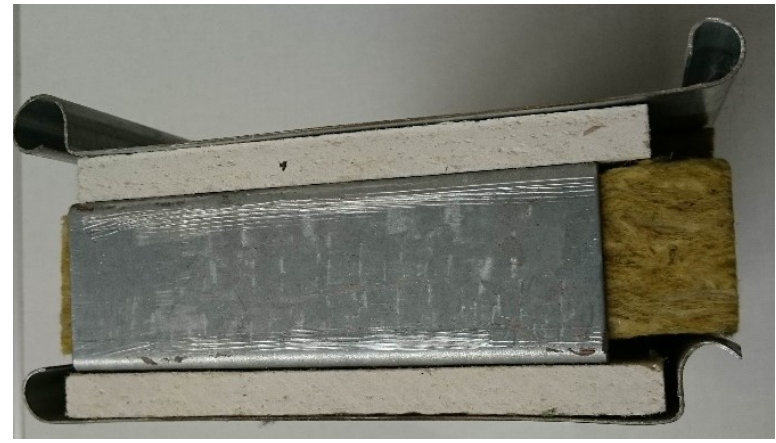

Fig. 1. Cross section of the lamella

\subsection{Experimental device}

The experiment was executed in chamber with dimension $1 \times 1 \times 1$ meter. The sample with dimension of $1 \times 1 \mathrm{~m}$ created one vertical wall of the testing chamber. On outer side of the sample four thermocouples were placed into the square shape in the centre of sample. For heating a propane /butane gas was applied. The one burner was placed on vertical side longitudinally to the sample. The temperature was regulated manually depending on the required heating curve in accordance with average temperature measured in chamber by six thermocouples.

\section{Experiments}

The combustion process in the chamber is accompanied by a flow of gas, air and combustion products. This process will affect the distribution of heat in the chamber and around the sample. The temperature field on the surface of the sample facing towards the fire should not show significant variations with regard to position.

For heat loading a standardized heating curve was applied. Its course is done by the equation (eg. 1).

\subsection{Temperature on a sample}

Fig. 2 shows temperature on outer side of the sample. The thermocouple signal was averaged and obtained data was put in the graph. There is also added the standardized curve.

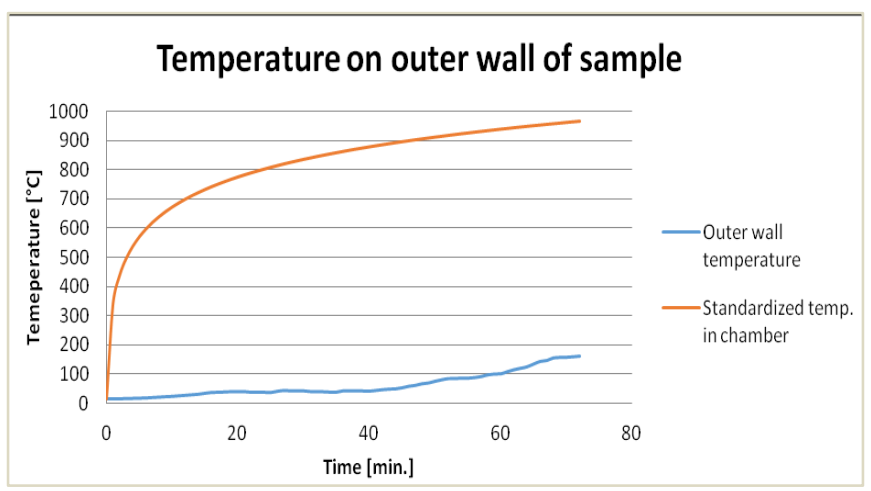

Fig. 2. Experimental results of temperature taken on outer sample surface

\section{Numerical simulation}

Analytical or numerical solution of turbulent flow problems can be achieved using various levels of approximation. The easiest approach to modeling combustion is according to [5] use semi-empirical correlations, Moody's diagram or a more sophisticated method involves the use of Reynolds' averaging (2):

$$
\langle f\rangle=\frac{1}{T} \int_{t}^{t+T} f(\tau) d \tau
$$

Where $f$ is the long time average of quantity and $\mathrm{T}$ the time interval - longer than all the time scales of the turbulent flow.

If the averaging is applied to the equations of motion, we obtain the Reynolds-averaged Navier-Stokes equations (RANS) that describe the evolution of the mean quantities [6].

The effect of turbulent fluctuations appears in a Reynolds stress term must be modeled to close the system $[6,7]$.

Used software PyroSim (Fire Dynamics Simulator developed at NIST) solves the Navier-Stokes equations using the Large Eddy Simulation method. This solution is transient and will vary with time at any point $[7,8]$. In contrast, the Reynolds Averaged Navier-Stokes approach provides a single time averaged solution. Large-eddy simulations (LE) are a technique between the direct simulation of turbulent flows and the solution of the Reynolds-averaged equations.

If a sufficiently refined mesh is used, FDS can accurately simulate a free jet. If the mesh refinement is too coarse, the solution will not observe turbulence in the shear layer that entertains the surrounding fluid and the predicted centerline velocity will not decay [8]. Generally, it is of course better to assess the quality of the mesh size in terms of nondimensional parameter, rather than an absolute size.

In FDS is the cell ratio used to describe relative mesh size. Due to the accuracy the cell ratio should not been bigger than $1 / 5$ of the characteristic fire diameter. According to $[6,8]$ a mesh of even $1 / 16$ the jet side is needed to obtain a reasonably accurate solution. 


\subsection{Model definition}

The non-premixed combustion model with a mixture of propane-butane $(\mathrm{C} 2 \mathrm{H} 6, \mathrm{CH} 4)$ has been created. The LE theorem and the solution with considered baroclinic torque and the non ideal energy approach, that consider arising $\mathrm{CO}, \mathrm{H}_{2}$ and soot, has been used.

Three-dimensional flow was modelled by large Eddy model. Particle of defined gas, presented a moveable fragmented droplets (5000 per second), have been through nozzle sprayed into a model domain with defined volume flow rate $(\mathrm{L} / \mathrm{min})$, velocity $(\mathrm{m} / \mathrm{s})$ through a $12 / 10^{\circ}$ conical jet. The value of the volume flow was necessary to adjust during the process of combustion, in order to hold the normalized temperature. That was done in ten time steps, and as could be seen in the Fig. 3, there is possible to recognize a small changing of the tangent vector. In specific processes such as atomization or spraying a wide variety of mathematical and empirical distribution functions, such as the normal, log-normal or Rosin-Rammler distribution of particles is used [9, 10]. The particles with median diameter $50 \mu \mathrm{m}$ via RosinRammler log normal function have been distributed. This statistical model is suitable for description of materials composed of huge number of small particles like powder, emulsion and in our case small gas particles. More about using of this technique could be read there [11, 12].

As had been already mentioned, the model of combustion are really sensitive to amount of small details, where the vortexes and nonlinearities arising. Because of that, it was necessary to create several model domains, with the best quality of the mesh in the place, where the jet is located and where the fire process is happen. This could be seen in the Fig. 3, where also the thermocouples used for measuring the in/out temperature and the tested layered sample are.

\subsection{Results and discussion of numerical simulation}

At the carried simulation we were primarily interested in the most accurate definition of the fire and subsequent in studying its effects on the tested layered sample. The most important results for us is how the heat is transferred through the sample and especially the temperature measured on the outside sheet.

First results showed different course of sample temperatures in initial state of the heating. In the graph (Fig. 4) a less steep rise in the temperature of the real sample can be observed compared to a model that shows a rapid increase in temperature range $0-10$ minutes. The experimental curve is fitted by the polynomial function. The cause has been investigated and an explanation could be the fact that gypsum contains big amount of water, especially under high relative humidity.

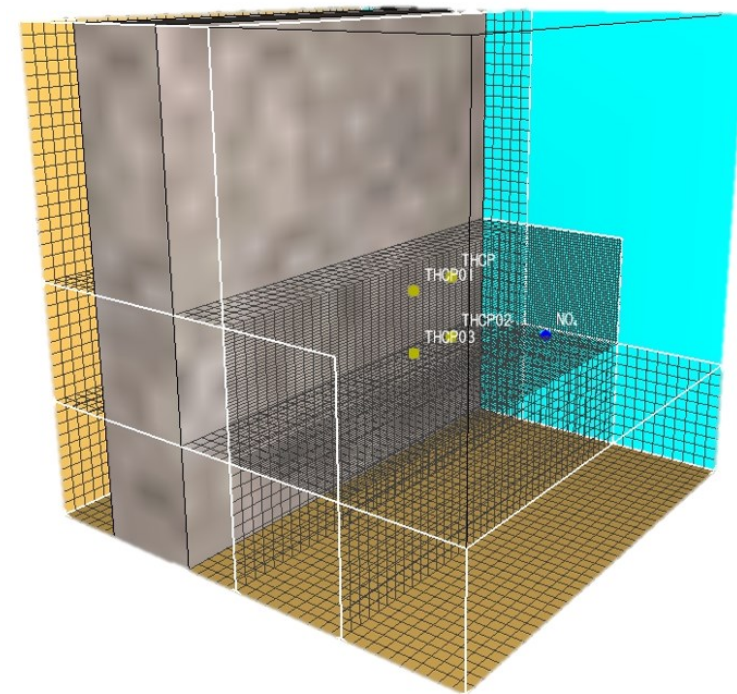

Fig. 3. The inner mesh bases and devices of the model

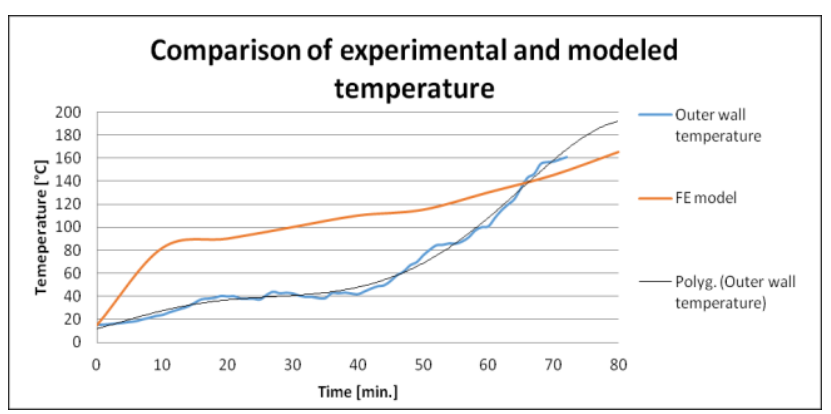

Fig. 4. Experimental and FE model temperatures

In the experiment calcium sulphate dihydrate (CaSO4-2H2O) was applied. Thus, the water is chemically bonded. Also it can be underlined that this type of the gypsum is significantly porous and water is physically bonded in pore channels. Under higher relative humidity these channels are full filled with the water. If higher temperature above $100^{\circ} \mathrm{C}$ is applied, water receives an energy required for its warming, then the energy required for state change (from liquid to steam) and the energy required for the heating of steam to temperatures above $100^{\circ} \mathrm{C}$. If these energies are compared with tabled energy of gypsum (Tab. 2), then it can be concluded that for the model the change of the energy depending on temperature is required. This could be done by setting a table dependency of the material conductivity on temperature either directly in the material, or at any of chosen thermocouple used in the model.

Table 2. Energy for heating of wet gypsum

\begin{tabular}{|c|c|c|c|}
\hline Specific heat capacity $\left[\mathrm{J}_{\mathrm{kg}}{ }^{-1} \cdot \mathrm{K}^{-1}\right]$ & $\begin{array}{c}\text { Specific heat of } \\
\text { boiling }\left[\mathrm{kJ} \cdot \mathrm{kg}^{-1}\right]\end{array}$ & $\begin{array}{c}\text { Enthalpy of } \\
\text { saturated water } \\
{\left[\mathrm{kJ}^{\mathrm{k}} \mathrm{kg}^{-1}\right]}\end{array}$ \\
\hline Gypsum & & Water \\
\hline 490 & 4180 & 2257 & 2670 \\
\hline
\end{tabular}

It is evident that higher influence has water content and the coefficient has to be depending on the temperature, especially in range of 0 to $100^{\circ} \mathrm{C}$. Also thermal conductivity coefficient $\lambda$ will be in this range higher. 
The results after the refinement of this coefficient are more close to reality how it is seen in Fig. 5.

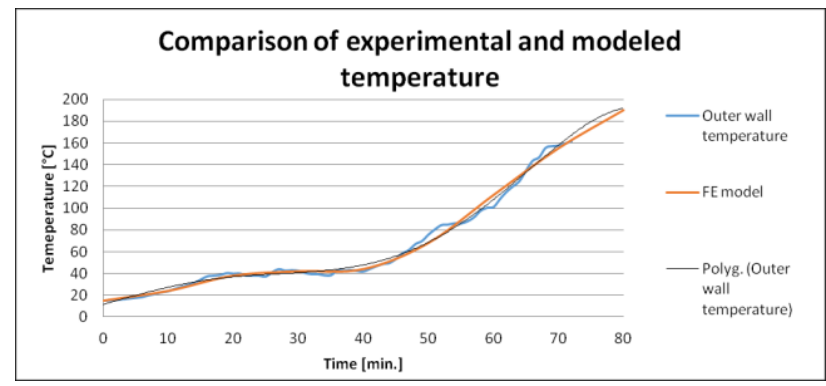

Fig. 5. FE model with modified material parameters

A graphical representation of results is put in Fig. 613. They show time course of temperatures each ten minutes from 0 to $70 \mathrm{~min}$.
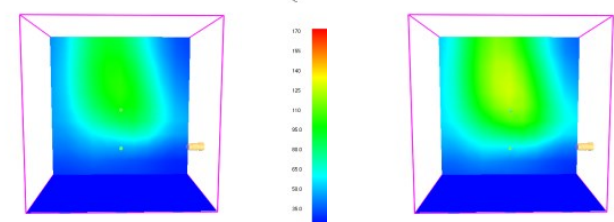

Fig. 6. and 7. Temperatures at time 0 and $10 \mathrm{~min}$.
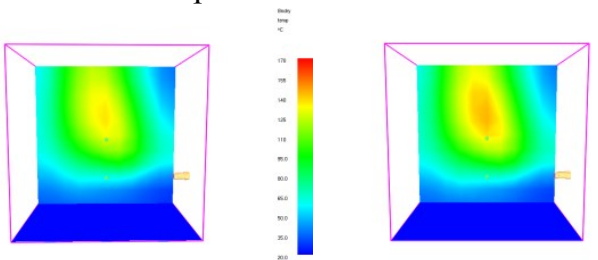

Fig. 8. and 9. Temperatures at time 20 and $30 \mathrm{~min}$.
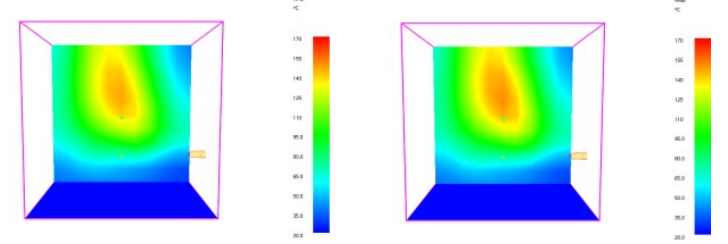

Fig. 10. and 11. Temperatures at time 40 and $50 \mathrm{~min}$.
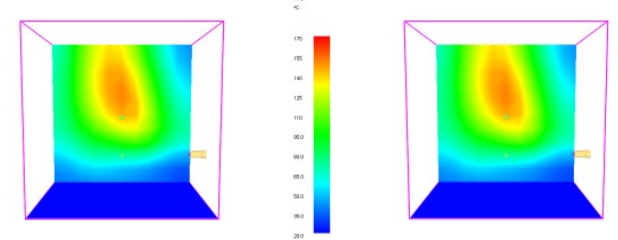

Fig. 12. and 13. Temperatures at time 60 and $70 \mathrm{~min}$.

The experimental and numerical determination of the temperatures arising on the sample are in quite a good conformity. From the ordinary identifiable physical properties, which can be accurately determined experimentally it was in the fuel definition necessary to gone through the description of quantum chemical particles. At this moment, is due to the complexity of solved task necessary to rely on literature, which is based on empirically verified and tested data $[1,5,10,11,12]$. After a thorough study of this issue is using and adjusting of these parameters advisable to tweak the simulation nearer the experiment.

\section{Conclusion}

In the case of a fire inside building it is necessary to limit the spreading by the safe isolation fire zones, ie. the closure of fire doors. In the presented work the new fire shutter consisted on combination of heat-resistant materials was shown. Using the software Pyrosim from the manufacturer Nist, the numerical model based on Large Eddy approach has been created.

In comparison of the simulation and experiment, we can talk about a relatively good agreement in the measured temperatures inside and outside the reference sample (inner and outer sheets). Use of simulation is therefore very suitable for direct determination of the moment and duration critical temperature values which must be coordinated with the knowledge obtained during the experiment. It should be emphasized that some parameters in material model has to be changed based on measurements of samples under high temperatures and also on experience.

\section{Acknowledgments}

The results of this project VI20152018046 were obtained with co-funding from the Ministry of the Interior of the Czech Republic as part of targeted support from the project "Využití moderních metod modelování při vývoji a zkoušení protipožárních uzávěrů".

\section{References}

1. P. Kulhavy, T. Martinec, O. Novak, M. Petru and P. Srb, Testing fireproof materials in a combustion chamber, EPJ Web of Conf. 143, 02058 (2017)

2. R. L. Webb, N. KIM, Principles of enhanced heat transfer, Taylor \& Francis, (2005)

3. ČSN EN 1363-1 - Testing of fire resistance - Part 1, ÚNMZ, Praha, (2000)

4. ISO 834-10:2014 Fire resistance tests - Elements of building construction, (2014)

5. B. J. M. Giesen, et. al., Modelling and simulation of a jet fan, Env. Modelling and Software, 26, (2011)

6. U. Piomelli, Large-eddy: Achievements and challenges, Progress in Aerospace Sc., 35, (1999)

7. K. McGrattan, et al. Fire Dynamics Simulator Technical Reference Guide, 6, (2016)

8. FDS-SMV. Fire Dynamics Simulator, USA: National Ins. of Standards and Technology.

9. D. Frenkel, B. Smit, Understanding Molecular Simulation, San Diego: Academic Press, 2, (2002)

10. E. Jurado, et al, Estimation of the distribution of droplet size, Colloids and Surfaces A: Physicochem. Eng. Aspects, 295 (2007)

11. K. Akselvoll, P. Moin, Large-eddy simulation of turbulent conned jets, J. Fluid Mech., (1996)

12. A. H. Lefebvre, Atomization and Spray, Hemisphere Publishing, Washington, (1989) 